\title{
Alpha-1 antitrypsin deficiency targeted testing and augmentation therapy: A Canadian Thoracic Society clinical practice guideline
}

\author{
DD Marciniuk MD FRCPC FCCP ${ }^{1 *}, \mathrm{P}_{\text {Hernandez MDCM FRCPC }}^{2 \dagger}, \mathrm{M}$ Balter MD FRCPC FCCP ${ }^{3}$, \\ J Bourbeau MD MSC FRCPC ${ }^{4}$, KR Chapman MD MSC FRCPC FACP ${ }^{4}$, GT Ford MD FRCPC FCCP ${ }^{5}$, \\ JL Lauzon MD MHSC FRCPC FCCMG ${ }^{5}$, F Maltais MD FRCPC ${ }^{6}$, DE O'Donnell MD FRCPI FRCPC ${ }^{7}$, \\ D Goodridge $\mathrm{RN} \mathrm{PhD}^{1 \ddagger}, \mathrm{C}$ Strange $\mathrm{MD}^{8 \S}$, AJ Cave MB ChB FCFP FRCGP9§, K Curren MA ${ }^{10}$, S Muthuri MSC ${ }^{10}$; \\ Canadian Thoracic Society COPD Clinical Assembly Alpha-1 Antitrypsin Deficiency Expert Working Group
}

\begin{abstract}
D Marciniuk, P Hernandez, M Balter, et al; Canadian Thoracic Society COPD Clinical Assembly Alpha-1 Antitrypsin Deficiency Expert Working Group. Alpha-1 antitrypsin deficiency targeted testing and augmentation therapy: A Canadian Thoracic Society clinical practice guideline. Can Respir J 2012;19(2):109-116.
\end{abstract}

Alpha-1 antitrypsin (A1AT) functions primarily to inhibit neutrophil elastase, and deficiency predisposes individuals to the development of chronic obstructive pulmonary disease (COPD). Severe A1AT deficiency occurs in one in 5000 to one in 5500 of the North American population. While the exact prevalence of A1AT deficiency in patients with diagnosed COPD is not known, results from small studies provide estimates of $1 \%$ to $5 \%$. The present document updates a previous Canadian Thoracic Society position statement from 2001, and was initiated because of lack of consensus and understanding of appropriate patients suitable for targeted testing for A1AT deficiency, and for the use of A1AT augmentation therapy. Using revised guideline development methodology, the present clinical practice guideline document systematically reviews the published literature and provides an evidence-based update. The evidence supports the practice that targeted testing for A1AT deficiency be considered in individuals with COPD diagnosed before 65 years of age or with a smoking history of $<20$ pack years. The evidence also supports consideration of A1AT augmentation therapy in nonsmoking or exsmoking patients with COPD (forced expiratory volume in $1 \mathrm{~s}$ of $25 \%$ to $80 \%$ predicted) attributable to emphysema and documented A1AT deficiency (level $\leq 11 \mu \mathrm{mol} / \mathrm{L}$ ) who are receiving optimal pharmacological and nonpharmacological therapies (including comprehensive case management and pulmonary rehabilitation) because of benefits in computed tomography scan lung density and mortality.

Key Words: Alpha-1 antitrypsin; Augmentation therapy; Deficiency; COPD; Emphysema

A lpha-1 antitrypsin (A1AT) is the major antiprotease in plasma I and functions primarily to inhibit neutrophil elastase (1). A1AT deficiency occurs as a result of the inheritance of two proteinase inhibitor deficiency alleles located on chromosome 14 . The normal protein phenotype is PI*M, while the most common deficiency protein phenotype is $\mathrm{PI} Z \mathrm{Z}$. Protein phenotype $\mathrm{PI} * \mathrm{~S}$ is also a common deficiency phenotype and milder than PI*Z. Heterozygotes who are found to have one deficiency allele (usually PI*MZ, PI*SZ or $\mathrm{PI} * \mathrm{MS}$ ) are not considered to be at markedly increased risk for the development of severe chronic obstructive pulmonary disease (COPD) $(1,2)$, although it has been suggested that future studies that adjust for smoking and include other COPD-related phenotypes are required to conclusively determine the risk of COPD in PI*MZ heterozygotes (3). The presence of two deficiency alleles, most commonly PI*ZZ, results in significantly reduced serum levels of A1AT,

\section{Des tests ciblés sur le déficit en alpha-1 antitrypsine et le traitement substitutif : guide de pratique clinique de la Société canadienne de thoracologie}

L'alpha-1 antitrypsine (AAT) fonctionne principalement pour inhiber l'élastase neutrophile, et un déficit prédispose à l'apparition d'une maladie pulmonaire obstructive chronique (MPOC). On recense un déficit marqué en AAT chez un à 5000 à un à 5500 habitants de la population nordaméricaine. Bien qu'on ne connaisse pas la prévalence exacte de déficit en AAT chez les patients ayant une MPOC diagnostiquée, les résultats de petites études présagent des taux de $1 \%$ à $5 \%$. Le présent document est une mise à jour d'un énoncé de position de la Société canadienne de thoracologie publié en 2001 et a été amorcé à cause de l'absence de consensus et de compréhension quant aux patients se prêtant à un test ciblé de déficit en AAT et à un traitement de substitutif de l'AAT. Fondé sur une méthodologie révisée d'élaboration de directives, le présent guide de pratique clinique contient une analyse systématique des publications et fournit une mise à jour probante. Les données probantes appuient la pratique d'envisager un test ciblé de déficit en AAT chez les personnes ayant un MPOC diagnostiquées avant l'âge de 65 ans ou dont les antécédents de tabagisme sont de moins de 20 paquets par année. Les données probantes soutiennent également la pratique d'envisager un traitement substitutif de l'AAT chez les non-fumeurs ou les anciens fumeurs ayant une MPOC (volume expiratoire maximal par seconde de $25 \%$ à $80 \%$ des valeurs prévues) attribuable à un emphysème et à un déficit en AAT documenté (taux maximal de 11 $\mu \mathrm{mol} / \mathrm{L})$ qui reçoivent une thérapie pharmacologique et non pharmacologique optimale (y compris une prise en charge complète du cas et une réadaptation pulmonaire) en raison des améliorations de la densité pulmonaire à la tomodensitométrie et de la baisse de mortalité.

and is associated with a markedly increased risk for the development of panlobular emphysema and liver disease. Severe A1AT deficiency occurs in approximately one in 1600 of the Scandinavian population (4), and in approximately one in 5000 to 5500 of the Canadian and North American populations (5).

First described in 1963 (6), A1AT deficiency predisposes individuals to the development of emphysema and COPD, which is markedly accelerated and more severe in the presence of cigarette smoking and other cofactors, both environmental and genetic $(1,2)$. The exact prevalence of A1AT deficiency in patients diagnosed with COPD is not known, but results from small studies have provided estimates of $1 \%$ to $5 \%(1,2)$. Liver disease and the development of cirrhosis is the next most common clinical disease presentation (7) and may be a frequent cause of death in nonsmoking individuals with the $\mathrm{PI} Z \mathrm{ZZ}$ protein phenotype (8).

${ }^{1}$ University of Saskatchewan, Saskatoon, Saskatchewan; ${ }^{2}$ Dalhousie University, Halifax, Nova Scotia; ${ }^{3}$ University of Toronto, Toronto, Ontario;

${ }^{4} \mathrm{McGill}$ University, Montreal, Quebec; ${ }^{5}$ University of Calgary, Calgary, Alberta; ${ }^{6}$ Laval University, Laval, Quebec; ${ }^{7}$ Queen's University,

Kingston, Ontario; ${ }^{8}$ Medical University of South Carolina, Charleston, South Carolina, USA; ${ }^{9}$ University of Alberta, Edmonton, Alberta;

${ }^{10}$ Canadian Thoracic Society, Ottawa, Ontario

*Chair, Canadian Thoracic Society Alpha-1-Antitrypsin Deficiency Expert Working Group; ${ }^{\dagger}$ Chair, Canadian Thoracic Society COPD Clinical

Assembly; ${ }^{\ddagger} \mathrm{Co}-\mathrm{Chair}$, Canadian Thoracic Society COPD Clinical Assembly; ${ }^{\S}$ Expert Reviewer

Correspondence/Requests for reprints: Dr Darcy D Marciniuk, Canadian Thoracic Society, 300-1750 Courtwood Crescent, Ottawa,

Ontario K2C 2B5. Telephone 613-569-6411, fax 613-569-8860, e-mail ctsinfo@lung.ca 
A1AT protein phenotypes most strongly linked with pulmonary emphysema and COPD are associated with A1AT plasma levels below $11 \mu \mathrm{mol} / \mathrm{L}$. The protease-antiprotease imbalance attributable to A1AT deficiency results in unopposed activity of leukocyte elastases with consequent degradation of elastin and other extracellular matrix components of the respiratory tract. These mechanisms are also believed to be stimulated by the presence of cigarette smoking alone, but the resultant development of emphysema is accelerated when tobacco smoke exposure and A1AT deficiency coexist. The administration of intermittent A1AT intravenous therapy has been demonstrated to significantly increase A1AT levels both in serum and in lung epitheliallining fluid (bronchoalveolar lavage fluid) (9).

The Canadian Thoracic Society (CTS) previously published a position statement on A1AT deficiency in 2001 (1), which was an update of an earlier CTS Standards Statement originally developed in 1992 (10). The topic has also been examined by others $(2,11,12)$. The present clinical practice guideline document systematically reviews the published literature in this area, and provides an evidence-based update using revised guideline development methodology (described below).

The present guideline statement presupposes that appropriate and optimal pharmacological therapies have been administered. The statement further assumes that nonpharmacological therapies, including smoking cessation, vaccinations, pulmonary rehabilitation, self-management skills, comprehensive case management and surgical therapies, have been and continue to be optimally used in the management of all COPD patients with A1AT deficiency.

\section{TARGET POPULATION}

The present clinical practice guideline provides direction on targeted testing and augmentation therapy for A1AT deficiency in COPD patients. For this purpose, patients with COPD have a forced expiratory volume in $1 \mathrm{~s}\left(\mathrm{FEV}_{1}\right) /$ forced vital capacity $(\mathrm{FVC})<0.7$, as defined by the CTS $(13,14)$ and by the Global Initiative for Chronic Obstructive Lung Disease (GOLD) (15). Patients with A1AT deficiency are defined as $\mathrm{Pi}^{*} \mathrm{ZZ}, \mathrm{Pi}^{*} \mathrm{Z}$ (null) and $\mathrm{Pi}$ (null)(null) protein phenotypes (and other rare A1AT disease-causing alleles) with documented A1AT levels below $11 \mu \mathrm{mol} / \mathrm{L}$. The present clinical practice guideline does not address liver disease, necrotizing panniculitis, antineutrophil-cytoplasmic-positive vasculitis or mass screening/ targeted testing of neonates.

\section{TARGET USERS}

The present document is intended for all health care professionals involved in the care of patients with COPD attributable to A1AT deficiency and in the care of respiratory patients for whom targeted testing of A1AT deficiency is being considered. They include respirologists, family physicians, internists, nurses, health care administrators and health care systems.

\section{Guideline development process}

\section{METHODOLOGY}

The CTS A1AT deficiency targeted testing and augmentation therapy clinical practice guideline was developed by a panel of representative professionals involved in the care of patients with COPD and A1AT deficiency. The overall process was coordinated by the CTS Respiratory Guideline Committee and staff, with the assistance of consultant librarian and methodology experts. The guideline was developed in accordance with the convention of the 23-item Appraisal of Guidelines Research and Evaluation (AGREE) II instrument (16). The research questions were prepared based on the Working Group's recognition of clinical care gaps and solicited needs of the target populations. Questions were constructed in accordance with a 'PICO' process, taking into consideration the Problem, Intervention, Comparison and Outcomes within each research question, ensuring an appropriate and answerable question was constructed. The process enabled the development of a search strategy that outlined the types of studies, main topics and terms, inclusion and exclusion criteria used in the search, as well as suitable databases for the search.

\section{Literature search}

Based on the criteria outlined within the search strategy for each of the research questions, MEDLINE, EMBASE, the Cochrane Library, the Canadian Medical Association InfoBase and the National Guideline Clearinghouse were searched for pertinent published literature between January 1, 1980, and September 8, 2011. In addition, supplementary references of selected articles and recent review articles were also scanned by the Expert Working Group members for additional citations.

Articles were selected for inclusion in the systematic review of the evidence if they were English or French articles reporting data on targeted testing of adult individuals with suspected A1AT deficiency, or of augmentation therapy among adult individuals with A1AT deficiency. In descending order of preference, minimum levels of evidence needed to inform the clinical questions were meta-analyses of randomized controlled trials (RCTs), RCTs, nonrandomized comparative studies or observational studies involving a minimum of 50 patients.

\section{Evidence selection}

An initial review of abstracts was performed to inform article selection for which the full text was required, with four Working Group members assigned to each research question. All abstracts were reviewed by two group members. Once full-text articles were retrieved, data extraction tables were used to systematically extract evidence from included/relevant full-text articles based on the predetermined inclusion and exclusion criteria supporting the research question. These tables were used to summarize and organize information (ie, study design, target population, interventions, outcomes, functional and clinical significance of findings) for formulation of recommendations and supporting narrative text. Another group member verified all evidence extracted into tables. Data extraction tables are available as online supplemental material (www.respiratoryguidelines.ca). Narrative text of key evidence and conclusions supporting recommendations were completed based on the data extracted.

Articles assessing targeted testing of adult individuals with suspected A1AT deficiency were evaluated for the following outcomes: improvement in case-finding, reduction in dyspnea, improved exercise capacity, improved activity, decreased exacerbations, decreased health care use and improved quality of life/health status. Articles assessing A1AT augmentation therapy were evaluated for the following outcomes: decreased exacerbations, improved quality of life/health status, reduction in dyspnea, improved exercise capacity, improved activity, decreased health care use, reduction in mortality, reduction in rate of lung function decline and stabilization of computed tomography (CT) scan-quantified lung density.

\section{Formulating recommendations}

Decisions regarding the strength of recommendations (Table 1) were achieved through a formal consensus process whereby Working Group members assigned to each of the research questions considered the strength of the evidence using the Grading of Recommendation Assessment, Development and Evaluation (GRADE) methodology (17). In addition, adverse effects, health benefits to patients, the burden on the patient associated with adherence to the recommendations, extent to which the evidence directly addressed the research question, and impact on morbidity, mortality and quality of life were considered $(17,18)$. Final consensus on the recommendations by the Working Group was achieved via a distinct voting process, with agreement reported as a percentage of Working Group members. Extensive discussions were used to edit, correct and revise the document.

\section{External expert commentary and review}

Expert reviewers identified by the Working Group and the Canadian Respiratory Guidelines Committee on the basis of their clinical and methodological expertise, were invited to review the document. A draft of the clinical practice guideline was circulated to the reviewers, 
TABLE 1

\section{Strength of evidence and grading of recommendations}

\begin{tabular}{|c|c|c|}
\hline \multirow[t]{3}{*}{$\begin{array}{l}\text { Quality of } \\
\text { evidence }\end{array}$} & Grade A & $\begin{array}{l}\text { Well-designed randomized controlled trials } \\
\text { with consistent and directly applicable } \\
\text { results }\end{array}$ \\
\hline & Grade B & $\begin{array}{l}\text { Randomized trials with limitations including } \\
\text { inconsistent results or major methodological } \\
\text { weaknesses }\end{array}$ \\
\hline & Grade C & $\begin{array}{l}\text { Observational studies, and from } \\
\text { generalization from randomized trials in one } \\
\text { group of patients to a different group of } \\
\text { patients }\end{array}$ \\
\hline \multirow[t]{2}{*}{$\begin{array}{l}\text { Strength of } \\
\text { recommendation }\end{array}$} & Grade 1 & $\begin{array}{l}\text { Strong recommendation, with desirable } \\
\text { effects clearly outweighing undesirable } \\
\text { effects (or vice versa) }\end{array}$ \\
\hline & Grade 2 & $\begin{array}{l}\text { Weak recommendation, with desirable effects } \\
\text { closely balanced with undesirable effects }\end{array}$ \\
\hline
\end{tabular}

Adapted from references 17 and 19

feedback was gathered and relevant changes were incorporated into the document. Reviewers also used a short AGREE II (16) checklist to document their appraisal and enhance the usability of the document.

The present document, including the questions and content, will be regularly reviewed and updated to reflect the changing and growing body of evidence in this area. At a minimum, after a five-year period, the literature will be reviewed for new and compelling evidence to further inform or revise the guideline recommendations.

\section{SECTION I}

Question

Which populations are most appropriate for targeted testing of A1AT levels to improve case-finding of patients at risk of or with documented lung disease associated with A1AT deficiency?

\section{Introduction}

Targeted testing for A1AT deficiency is performed to establish diagnosis in individuals at risk for disease, to inform and provide recommendations to patients and to optimize clinical management (ie, exposure to tobacco smoke, biomass and other environmental pollutants, minimize respiratory infections, etc). It is also used to support genetic counselling of patients and family members (see Discussion).

Key evidence

A total of 1081 abstracts were initially identified by the search, of which 57 full-text articles were selected for complete review. Seven studies fully met the criteria and were selected for data extraction and utilization in the present review (Table 2). These studies assessed whether there was an increased rate of A1AT deficiency and/or abnormal protein phenotypes in several patient populations with known chronic lung disease, historically considered to be at increased risk.

Three studies examined the role of targeted testing for A1AT deficiency in patients with COPD (20-22). Sørheim et al (20) reported the combined results of two well-characterised study populations. One population was from a case-control study of adults conducted in Norway (Caucasians, $\geq 40$ years of age, current or exsmokers of $>2.5$ pack years), in which 834 cases had evidence of airflow obstruction on spirometry and 835 control subjects had normal spirometry. The second population came from an international COPD genetics study of 984 COPD subjects ( 45 to 65 years of age, current or exsmokers of $\geq 5$ pack years, airflow obstruction on spirometry) and 1723 relatives. Compared with $\mathrm{Pi}^{*} \mathrm{MM}$ individuals, heterozygotes ( $\mathrm{Pi}^{*} \mathrm{MZ}$ ) had a lower $\mathrm{FEV}_{1} / \mathrm{FVC}$ ratio. In individuals with lower smoking exposure $(<20$ pack years), $\mathrm{Pi}^{*} \mathrm{MZ}$ was associated with more severe emphysema scores on CT scan. Another study evaluated an outpatient population with obstructive lung disease (21), which included COPD, asthma and bronchiectasis, and found no increased frequency of severe A1AT deficiency
TABLE 2

Literature search results informing recommendations

\begin{tabular}{|c|c|c|}
\hline Section & Topic & $\begin{array}{l}\text { Studies informing } \\
\text { recommendations, } \mathrm{n} \\
\text { (References) }\end{array}$ \\
\hline I & $\begin{array}{l}\text { Which populations are most appropriate } \\
\text { for targeted testing of A1AT levels, to } \\
\text { improve case-finding of patients at risk } \\
\text { of or with documented lung disease } \\
\text { associated with A1AT deficiency? }\end{array}$ & $7(20-26)$ \\
\hline II & $\begin{array}{l}\text { Is A1AT augmentation therapy effective } \\
\text { in COPD patients with documented } \\
\text { A1AT deficiency? }\end{array}$ & $6(11,33-36,38)$ \\
\hline
\end{tabular}

A1AT Alpha-1 antitrypsin; COPD Chronic obstructive pulmonary disease

or abnormal allele at the Pi locus compared with rates reported in the general population. A case-control database linkage study derived from two Danish registries (patients with A1AT deficiency, general population) (22) reported an increased risk for hospitalization with a diagnosis of COPD or asthma, but no increase in mortality among heterozygotes $(\mathrm{Pi} * \mathrm{MZ})$ compared with matched controls.

Four studies examined the role of targeted testing for A1AT deficiency in patients with asthma (21-24). No study found an increased frequency in severe A1AT deficiency or abnormal alleles at the $\mathrm{Pi}$ locus compared with rates reported in control populations. Three studies examined the role of targeted testing for A1AT deficiency in patients with bronchiectasis $(21,25,26)$. Only one small case-control study reported a possible increased frequency of the $\mathrm{Z}$ allele among patients with bronchiectasis and common variable immunodeficiency (25), although radiographic evidence of bronchiectasis is often seen in patients with $\mathrm{Pi} * \mathrm{ZZ}$ deficiency (27).

Well-known risk factors for lung cancer are tobacco smoking and COPD. Two hypothesis-generating studies investigated the possible role of abnormal alleles at the Pi locus as an additional risk factor for lung cancer $(28,29)$. Preliminary findings suggested that heterozygote individuals for A1AT ( $\mathrm{Pi} * \mathrm{MS}, \mathrm{Pi}^{*} \mathrm{MZ}$ or $\left.\mathrm{Pi} \mathrm{MI}\right)$ were at increased risk for developing lung cancer, particularly squamous cell and bronchoalveolar cell types.

A longitudinal cohort study assessed the contribution of A1AT deficiency or abnormal alleles on symptoms and rate of lung function decline in New York (USA) fire department rescue workers following the World Trade Centre (WTC) collapse in 2001 (30). Mild (Pi*MZ) A1AT deficiency was associated with persistent cough and accelerated rate of $\mathrm{FEV}_{1}$ decline in the immediate four years following the WTC collapse. These findings highlight the possible anti-inflammatory role of A1AT, not only in the setting of chronic exposure to airborne pollutants such as tobacco smoke, but also following acute exposure to intense inflammatory stimuli, such as occurred after the WTC collapse.

\section{Conclusions}

Although the CTS Expert Working Group recommendations are derived from limited data, there may be benefit from early detection in selected populations including behaviour modification, optimized clinical management and enhanced genetic counselling. The age stratification is included in the recommendation because it was the only well-defined population studied. Individuals identified in the recommendations should undergo assessment of A1AT serum or plasma protein levels. However, there may be a role for testing individuals older than 65 years of age for the purpose of family studies and genetic counselling. In addition, it was the consensus of the Working Group that family members of individuals with documented A1AT deficiency also be offered genetic counselling and A1AT level testing, with attention devoted to siblings whose risk of A1AT deficiency is $25 \%$. 
There was also recognition that individuals with A1AT deficiency may be misdiagnosed with asthma - the recommendations assume the correct diagnosis is established (31). In the presence of diagnostic uncertainty (for example, persistent obstruction on lung function testing) and if A1AT deficiency is a clinical diagnostic possibility, testing may be indicated. Due to the complexity of testing and interpretation of results, referral to a respirologist and/or geneticist should be considered.

\section{QUESTION 1}

Which populations are most appropriate for targeted testing of A1AT levels to improve case-finding of patients at risk of or with documented lung disease associated with A1AT deficiency? The following recommendations are based on evidence from seven studies and expert consensus of the CTS A1AT Deficiency Expert Working Group.

\section{RECOMMENDATION 1A*}

We suggest targeted testing for A1AT deficiency be considered in individuals with COPD diagnosed before 65 years of age or with a smoking history of $<20$ pack years. (Grade of recommendation: $2 \mathrm{C}$ )

\section{RECOMMENDATION $1 \mathrm{~B}^{\dagger}$}

We suggest targeted testing for A1AT deficiency not be undertaken in individuals with bronchiectasis or asthma. (Grade of recommendation: 2C)

*100\% agreement was achieved for Recommendation 1 A; ${ }^{\dagger} 90 \%$ agreement was achieved for Recommendation 1B (complete agreement was not achieved because some believed there was evidence supporting targeted testing in these selected populations).

\section{SECTION II}

\section{Question}

Is A1AT augmentation therapy effective in COPD patients with documented A1AT deficiency?

\section{Introduction}

A1AT deficiency is a rare disease, and a permanent cure for the lung disease is not available. By administering the A1AT protein to those who are severely deficient, the belief is that progression of emphysema may be prevented or that significant improvement may occur. Previous reviews have provided discordant recommendations for the use of A1AT augmentation therapy in the clinical setting. Some have stated it is "irresponsible" to recommend the use of A1AT augmentation therapy (32, which as stated by the authors, is 'similar' to reference 11), while others have recommended "intravenous augmentation therapy for individuals with established airflow obstruction from AAT deficiency" (2). Predictably, this has led to confusion among health care providers regarding the use of A1AT augmentation therapy.

\section{Key evidence}

A total of 1399 abstracts were identified by the search, of which 41 articles were selected for complete review. Six studies fully met the criteria and were selected for data extraction and use in the present review (Table 2).

Two RCTs directly examined this question. The first trial (33) randomly assigned 56 never or exsmoking subjects with A1AT deficiency ( $\mathrm{Pi}^{*} \mathrm{ZZ}$ ) and emphysema, and an $\mathrm{FEV}_{1}$ between 30\% and $80 \%$ predicted, to once-monthly intravenous infusions of purified A1AT $250 \mathrm{mg} / \mathrm{kg}$ or placebo (albumin) for at least three years. The primary outcome was to compare the rate of decline in $\mathrm{FEV}_{1}$, which demonstrated no significant difference between the A1AT-treated and placebo groups. The annual mean $( \pm \mathrm{SD})$ rate of decline in $\mathrm{FEV}_{1}$ in the placebo group was $25.2 \pm 22.0 \mathrm{~mL}$ and the rate of decline in the treatment group was $26.5 \pm 15.1 \mathrm{~mL}(\mathrm{P}=0.96)$. Secondary outcomes included pulmonary function and quantitation of emphysema using CT scan. No differences in vital capacity or diffusing capacity of the lung for carbon monoxide (DLco) were reported. A nonsignificant trend $(\mathrm{P}=0.07)$ suggested reduced loss of CT scan lung density among subjects receiving augmentation therapy $(2.6 \pm 0.41 \mathrm{~g} / \mathrm{L} /$ year for placebo versus $1.5 \pm 0.41 \mathrm{~g} / \mathrm{L} /$ year for the treatment group).

The second RCT is the largest placebo-controlled RCT of A1AT augmentation published to date (34), and was designed as a pilot study for the end point of CT scan-measured lung density. Seventy-seven never or exsmoking A1AT-deficient subjects (A1AT level $\leq 11 \mu \mathrm{mol} / \mathrm{L}$ ) with $\mathrm{COPD}\left(\mathrm{FEV}_{1}\right.$ between $25 \%$ and $80 \%$ predicted) were randomly assigned to weekly infusions of augmentation therapy or placebo for two to 2.5 years. The primary study end point was lung density measured by CT scan. There were nonsignificant trends in CT scanassessed lung density favouring the treatment group (estimated treatment difference in mean slope of 15 th percentile lung density was 0.857 [ -0.065 to 1.778$] ; \mathrm{P}=0.07$ ). There was no difference in loss of lung function measured according to $\mathrm{FEV}_{1}$ and DLco between the two groups. Similarly, the mean annual COPD exacerbation rate was 2.55 in the augmented group and 2.19 in the placebo group $(\mathrm{P}=0.265)$. Finally, no clinically meaningful or statistically significant change in diseasespecific quality of life (according to St George's Respiratory Questionnaire) was found ( 1.48 fall in intervention group versus 2.37 fall in control group $[\mathrm{P}=0.695])$.

The data from these two RCTs were pooled and subsequently reanalyzed (35), recognizing there were differences in augmentation therapy dosing and CT density analyses. CT scan lung density was the primary study outcome, with decline in lung function being a secondary outcome. The pooled analysis demonstrated preservation of lung density among patients receiving augmentation therapy compared with study subjects who did not. The mean change in lung density from baseline was $-4.082 \mathrm{~g} / \mathrm{L}$ for A1AT and $-6.379 \mathrm{~g} / \mathrm{L}$ for placebo, with a treatment difference of 2.297 (95\% CI 0.669 to 3.926; $\mathrm{P}=0.006$ ). The $\mathrm{FEV}_{1}$ declined significantly and similarly in both the treated and placebo groups.

A meta-analysis of five studies has been performed (36): one RCT (33), three nonrandomized registry groups (37-39) and an abstract. The primary end point was the difference in $\mathrm{FEV}_{1}$ rate of decline (survival was intended to be a secondary end point, but was abandoned because of insufficient data). Patients receiving augmentation therapy had significantly lower rates of lung function decline than those who did not receive augmentation therapy. The decline in $\mathrm{FEV}_{1}$ was slower by $13.4 \mathrm{~mL} /$ year (95\% CI $1.5 \mathrm{~mL} /$ year to $25.3 \mathrm{~mL} /$ year) among all patients receiving augmentation therapy. This effect predominantly reflected results in the subset of patients with baseline $\mathrm{FEV}_{1}$ of $30 \%$ to $65 \%$ of predicted (decline in $\mathrm{FEV}_{1}$ was slower by $17.9 \mathrm{~mL} /$ year; $95 \%$ CI $9.6 \mathrm{~mL} /$ year to $26.1 \mathrm{~mL} /$ year).

Although survival data with respect to augmentation therapy are limited, a large registry study (38) showed that, in patients with baseline $\mathrm{FEV}_{1}$ values $<50 \%$ of predicted, significantly better survival was reported in patients receiving augmentation therapy (risk ratio $=0.64$ [95\% CI 0.43 to $0.94 ; \mathrm{P}=0.02]$ ). Whether patients did or did not receive augmentation therapy was not prospectively controlled and, hence, the finding may be confounded by uncontrolled factors that differed between the treated and untreated groups.

A recent Cochrane Review (11) included RCTs that compared patients randomly assigned to A1AT augmentation therapy with controls who were randomly assigned to placebo therapy $(33,34)$ (see above). The primary outcomes were mortality and $\mathrm{FEV}_{1}$; secondary outcomes included exacerbations, admissions, quality of life and DLco. Randomized controlled mortality data were not available, and there were no significant differences in $\mathrm{FEV}_{1}$ rate of decline, DLco, exacerbations or quality of life. Lung density deteriorated less in the active group compared with the placebo group; the statistically significant difference was $1.14 \mathrm{~g} / \mathrm{L}$ (95\% CI $0.14 \mathrm{~g} / \mathrm{L}$ to $2.14 \mathrm{~g} / \mathrm{L} ; \mathrm{P}=0.03$ ) over the course of the trials. No meaningful differences in harm from therapy were noted.

Augmentation therapy involves a purified blood product available in Canada from a single manufacturer and from a small number of commercial manufacturers worldwide; donor screening and subsequent purification, filtration and/or pasteurization processes differ among manufacturers. Reviews of adverse events do not suggest an increased 
risk of hepatitis, HIV or severe viral illnesses in treated patients. Adverse events are typically mild, and most commonly include headache, dizziness, dyspnea, fever and chills. The rate of adverse events has been estimated to be 0.02 to 0.03 events per patient per month of therapy, corresponding to two adverse events every five or more years. Adverse events account for only $3 \%$ of treatment discontinuations $(12,40)$.

\section{Conclusions}

The evidence demonstrates preservation of CT scan lung density with A1AT augmentation therapy, but no significant improvement in quality of life or exacerbations. The results for $\mathrm{FEV}_{1}$ rate of decline are contradictory, with one meta-analysis, predominantly of nonrandomized registry data (36), reporting an improvement with augmentation therapy, while small RCTs (underpowered for this end point and with significant limitations) reported no significant benefit with augmentation therapy. A single registry report suggested improved mortality for severe COPD patients and A1AT deficiency after augmentation therapy (38). A summary of effectiveness end points and results with A1AT augmentation therapy is provided in Table 3 .

There is ongoing debate regarding clinically meaningful end points in assessing the response to A1AT augmentation therapy. Emphysema leads to structural abnormalities of the lung that are best assessed pathologically. CT scan lung density has been shown to correlate with pathology scores in diseased lungs (41) and, may therefore, be a meaningful indicator of lung disease progression. Tanabe et al (42) undertook a two-year study of 60 COPD patients, 26 of whom experienced an exacerbation during the study. Although there were no statistically significant differences in the rate of decline in $\mathrm{FEV}_{1}$ or DLco between exacerbating and nonexacerbating COPD subjects, there was a statistically significant deterioration in CT scan lung density in COPD subjects who experienced exacerbations. In a cross-sectional study of A1AT deficient lung disease (43), CT scan lung density was shown to correlate with $\mathrm{FEV}_{1}$, airway conductance, gas-trapping, transfer factor and health status. Moreover, CT scan lung density may better predict mortality in A1AT deficiency than lung function parameters (44).

There are, however, important practical issues with using CT densitometry including lack of expertise in interpretation and lack of availability to most clinicians; multiple methods of measuring lung densitometry (ie, correcting for volume) with no yet agreed upon ideal method (45); and low inter- and intra-operator agreement regarding the extent of densitometry reduction that correlates with increasing severity of emphysema (46). It is anticipated some of these issues may be remedied by the publication of predicted lung densitometry normative values expected from ongoing lung cancer screening studies. In the interim, it is difficult to fully judge the magnitude of change in CT densitometry and its clinical significance when interpreting responses to A1AT augmentation therapies. Nonetheless, these differences have been objectively demonstrated with the use of A1AT augmentation therapy in patients with COPD attributable to A1AT deficiency.

A1AT augmentation therapy initiated as suggested in the recommendation should not routinely be discontinued if lung function deteriorates or falls below the lower $\mathrm{FEV}_{1}$ cut-off.

\section{QUESTION 2}

Is A1AT augmentation therapy effective in COPD patients with documented A1AT deficiency?

The following recommendation is based on evidence from six studies and expert consensus of the CTS A1AT Deficiency Expert Working Group.

\section{RECOMMENDATION 2*}

We suggest A1AT augmentation therapy may be considered in nonsmoking or exsmoking patients with COPD (FEV ${ }_{1} 25 \%$ to $80 \%$ predicted) attributable to emphysema and documented A1AT (level $\leq 11 \mu \mathrm{mol} / \mathrm{L}$ ), who are receiving optimal pharmacological and nonpharmacological therapies (including comprehensive case management and pulmonary rehabilitation) because of benefits in CT scan lung density (Grade of recommendation: $2 \mathrm{~B}$ ) and mortality (Grade of recommendation: 2C).
TABLE 3

Effectiveness end points and results from alpha-1 antitrypsin augmentation therapy

\begin{tabular}{|c|c|}
\hline End point & Result (quality of evidence) \\
\hline Exacerbations & $\begin{array}{l}\text { No evidence of benefit with augmentation therapy } \\
\qquad \text { (Grade B) }\end{array}$ \\
\hline Quality of life & $\begin{array}{l}\text { No evidence of benefit with augmentation therapy } \\
\qquad \text { (Grade B) }\end{array}$ \\
\hline Dyspnea & Not studied \\
\hline Exercise performance & Not studied \\
\hline Activity limitation & Not studied \\
\hline Health care use & Not studied \\
\hline Mortality & Benefit with augmentation therapy (Grade C) \\
\hline $\begin{array}{l}\text { Lung function - rate of } \\
\text { FEV }_{1} \text { decline }\end{array}$ & $\begin{array}{l}\text { No evidence of benefit with augmentation therapy } \\
\qquad \begin{array}{c}\text { (Grade B })^{\star} \\
\text { Benefit with augmentation therapy } \\
(\text { Grade } \mathrm{C})^{\star}\end{array}\end{array}$ \\
\hline $\begin{array}{l}\text { Radiology - CT scan } \\
\text { lung density }\end{array}$ & $\begin{array}{l}\text { Benefit with augmentation therapy } \\
\text { (Grade B) }\end{array}$ \\
\hline
\end{tabular}

${ }^{*}$ Results from Grade $C$ evidence reported improvement; results from Grade $B$ evidence did not demonstrate significant benefit from augmentation therapy see text Section II, Conclusions for further explanation. CT Computed tomography; FEV ${ }_{1}$ Forced expiratory volume in $1 \mathrm{~s}$

*90\% agreement was achieved for this recommendation (complete agreement was not achieved as some believed there was insufficient high-quality evidence to make a recommendation for or against A1AT augmentation therapy in COPD patients with A1AT deficiency).

\section{DISCUSSION}

This process was initiated because of the perception of a lack of consensus and understanding of appropriate patients suitable for targeted testing for A1AT deficiency, and for the use of A1AT augmentation therapy. The purpose was to provide meaningful, practical guidance for targeted testing of A1AT deficiency, and for the use of A1AT augmentation therapy. Using an evidence-based, systematic review process, led by a representative interprofessional panel of experts in the field, the present clinical practice guideline has addressed several clinically meaningful questions. The evidence from the reviews, and the experience and guidance afforded by the Expert Working Group members, enabled the formulation of relevant recommendations, fully accepting that there are significant and large gaps in the scientific literature in this area.

A summary of reccommendations is provided in Table 4. The evidence supports the notion that targeted testing for A1AT deficiency be considered in individuals with COPD diagnosed before 65 years of age or with a smoking history of $<20$ pack years. However, there is insufficient evidence in the literature to support routine targeted testing for A1AT deficiency in individuals with bronchiectasis or asthma (if correctly distinguished from COPD). The evidence demonstrates significant slowing in the loss of CT scan lung density with A1AT augmentation therapy, but no significant improvement in quality of life or exacerbations. The results for $\mathrm{FEV}_{1}$ rate of decline are contradictory, with one meta-analysis, predominantly of nonrandomized registry data, reporting an improvement with augmentation therapy (36), while small RCTs (underpowered for the end point and with significant limitations) reporting no significant benefit with augmentation therapy (38). A single registry report suggested improved mortality for severe COPD patients $\left(\mathrm{FEV}_{1}<50 \%\right)$ and A1AT deficiency after augmentation therapy.

As highlighted, the present evidence-based clinical guideline statement presupposes that appropriate and optimal pharmacological as well as nonpharmacological therapies have been and continue to be used in the management of all COPD patients with A1AT deficiency $(13-15,47)$. In this setting, it is misguided to minimize the importance 
TABLE 4

\section{Summary of evidence-based recommendations and grading}

\begin{tabular}{|c|c|c|}
\hline Recommendation & Suggestion & $\begin{array}{l}\text { Grade of } \\
\text { recommendation }\end{array}$ \\
\hline$\overline{1 A}$ & $\begin{array}{l}\text { The Working Group suggests } \\
\text { targeted testing for A1AT } \\
\text { deficiency be considered in } \\
\text { individuals with COPD } \\
\text { diagnosed before } 65 \text { years of } \\
\text { age or with a smoking history of } \\
<20 \text { pack years }\end{array}$ & $2 \mathrm{C}$ \\
\hline $1 B$ & $\begin{array}{l}\text { The Working Group suggests } \\
\text { targeted testing for A1AT } \\
\text { deficiency not be undertaken in } \\
\text { individuals with bronchiectasis or } \\
\text { asthma }\end{array}$ & $2 \mathrm{C}$ \\
\hline \multirow[t]{3}{*}{2} & $\begin{array}{l}\text { The Working Group suggests } \\
\text { A1AT augmentation therapy may } \\
\text { be considered in nonsmoking or } \\
\text { exsmoking patients with COPD } \\
\text { (FEV } 125 \%-80 \% \text { predicted) } \\
\text { attributable to emphysema and } \\
\text { documented A1AT deficiency } \\
\text { (level } \leq 11 \mu \mathrm{mol} / \mathrm{L} \text { ), who are } \\
\text { receiving optimal } \\
\text { pharmacological and } \\
\text { nonpharmacological therapies } \\
\text { (including comprehensive case } \\
\text { management and pulmonary } \\
\text { rehabilitation) because of } \\
\text { benefits in: }\end{array}$ & \\
\hline & $\begin{array}{l}\text { - Computed tomography scan } \\
\text { lung density }\end{array}$ & $2 B$ \\
\hline & - Mortality & $2 \mathrm{C}$ \\
\hline
\end{tabular}

A1AT Alpha-1 antitrypsin; COPD Chronic obstructive pulmonary disease;

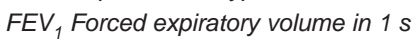

of these foundational interventions, and it is the perception of this Working Group that such therapies are underutilized. The Working Group believed it particularly important to consider augmentation therapy only in nonsmoking or exsmoking patients, considering the high cost of the therapy and, importantly, that current smokers were excluded from the RCTs evaluating the impact of augmentation therapy.

A1AT deficiency is caused by mutations in the SERPINA1 gene, which encodes the A1AT protease inhibitor $(\mathrm{Pi})$. There are three common testing strategies used to diagnose A1AT deficiency: measurement of serum or plasma A1AT protein level; A1AT protein phenotyping ( $\mathrm{Pi}$ typing); and A1AT genotyping. Measuring A1AT protein levels in serum or plasma is a reasonable initial test in individuals with suspected A1AT deficiency. A level below $20 \mu \mathrm{mol} / \mathrm{L}(113 \mathrm{mg} /$ dL) will detect $\mathrm{Pi}$ *MZ, Pi*SZ, PI*MS and PI*SS with 92\% sensitivity and $90 \%$ specificity $(2,48)$. A1AT protein level testing in serum alone is not useful for family studies because it does not provide information about the genetic variants involved. In particular, it cannot detect asymptomatic heterozygous carriers of A1AT deficiency who may have normal or near normal A1AT levels. In addition, if the A1AT deficiency is associated with a dysfunctional glycoprotein with normal A1AT serum or plasma levels, the diagnosis of A1AT deficiency may be overlooked (2). Determining the A1AT genotype can be accomplished either by $\mathrm{Pi}$ protein phenotyping, targeted DNA mutation analysis or gene sequencing. The normal Pi protein phenotype is $\mathrm{Pi}$ *M, which is most often associated with a normal MM genotype. The most common deficiency alleles are S (Glu34Lys) and Z (Glu264Val); while other Pi phenotypes include null alleles (which produce no A1AT protein) and dysfunctional alleles associated with normal protein levels, but abnormal protein function. Because Pi typing can only characterize 30 different protein phenotypes (49), rare variants or null alleles may be missed (48). Targeted DNA mutation analysis is limited to searching for common mutations such as $\mathrm{M}, \mathrm{S}$ and $\mathrm{Z}$, but can provide a presumptive genotype based on the presence or absence of $\mathrm{S}$ and $\mathrm{Z}$ mutations. Gene sequencing of the SERPINA1 gene is much less commonly undertaken. It is the most sensitive method for diagnosing A1AT deficiency, although it is expensive and not available in all centres.

Initial investigation of A1AT deficiency can be made by measuring A1AT levels, followed by characterization of Pi protein phenotype or genotype using targeted mutation analysis, which will enable confirmation of either a clinical diagnosis in a symptomatic individual, and a presymptomatic or carrier status in an at-risk family member. If no deficiency allele is detected in a symptomatic individual and the A1AT level is decreased, or there is a strong clinical suspicion that an at-risk individual has A1AT deficiency, full gene sequencing should be pursued (50).

Targeted testing performed in individuals at risk of disease either because of family history or signs and symptoms of disease is to be distinguished from population screening for which asymptomatic individuals are tested to identify those who may have abnormalities that could lead to future disease, especially in the presence of environmental modifying factors. As noted in the present document (Recommendations $1 \mathrm{~A}$ and $1 \mathrm{~B}$ ), screening populations of COPD patients older than 65 years of age, or all individuals with symptoms of COPD or other chronic lung disease, for A1AT deficiency is not supported by current evidence (21).

The literature describes A1AT deficiency both as an autosomal recessive and a codominant disorder. An affected individual has two abnormal deficiency alleles, and heterozygotes (or carriers) have one normal allele and one deficiency allele, both of which are expressed at the protein level. Heterozygotes are often asymptomatic, but may have mildly deficient A1AT levels. In counselling at-risk family members, siblings of severely deficient individuals should be offered testing because they have at least a $25 \%$ probability of sharing the full deficiency, a $50 \%$ probability of being carriers of A1AT deficiency with possibly mildly deficient A1AT levels, and a 25\% probability of having no deficiency. Offspring of an individual with two abnormal alleles would, at a minimum, be obligate carriers for A1AT deficiency. Whether they have A1AT deficiency is dependent on the carrier status of their other parent. It is important that the testing method offered to family members to clarify their A1AT status be able to detect the mutation type present in the proband (50). Finally, in addition to clarifying risks to family members, issues of nonpenetrance, the inability to predict age of onset, severity of disease and rate of progression (51), intra- and interfamilial variability, and possible insurance discrimination (52) with predictive testing in asymptomatic family members must be considered and addressed. Clinicians and individuals are strongly advised to seek the expertise of a clinical geneticist or specialized centre, and use appropriate genetic counselling for guidance or assistance in this area.

A1AT augmentation therapy is currently commercially available with an intravenous A1AT protease inhibitor derived from human plasma. The drug is approved by Health Canada for treatment of patients who clinically demonstrate panlobular emphysema and have congenital deficiency of alpha-1 antiprotease (patients with $\mathrm{Pi}^{*} \mathrm{ZZ}$, $\mathrm{Pi} * \mathrm{Z}[$ null] or Pi*[null][null] phenotypes).

As discussed, it is challenging to completely understand the implications of improvements (ie, less reduction) in CT scan densitometry. Nonetheless, consistent and repeatable differences have been objectively demonstrated with the use of A1AT augmentation therapy in patients with COPD attributed to A1AT deficiency.

The present evidence-based guideline document did not specifically study cost-effectiveness - this has been addressed elsewhere (12). Nonetheless, the Working Group recognized the high costs associated with A1AT augmentation therapy. Clinicians and patients must fully appreciate the costs associated with A1AT augmentation therapy during deliberations regarding the appropriateness of therapy. 


\section{FUTURE RESEARCH NEEDS}

It has become very apparent from this process that there is a paucity of high-quality evidence and scientific literature on this topic. Although this is a rare disease, further study is required to address several important clinical questions, and to provide further understanding and guidance for targeted testing for A1AT deficiency and A1AT augmentation therapy. It is the strong sense of the Working Group that additional small, descriptive trials of A1AT augmentation therapy will not provide further meaningful information or guidance regarding clinical efficacy. There is a pressing need for large RCTs, with long follow-up periods, assessing meaningful clinical end points. Such work should examine clinical effectiveness and undertake a detailed cost-analysis of A1AT augmentation therapy plus optimal usual care versus optimal usual care in A1AT-deficient COPD patients.

Advances in our understanding of the mechanisms leading to the development of emphysema and COPD in individuals with A1AT deficiency are necessary. The specific issue of early detection and potential early administration of augmentation therapy also requires additional investigation. Greater understanding of the prevalence of A1AT in selected populations is required. Acknowledging the significant current financial burden of A1AT augmentation therapy, additional work is required to explore more cost-effective means of developing and delivering therapy. These important research questions require attention to advance our understanding in this area.

\section{KNOWLEDGE TRANSFER AND TOOLS FOR PRACTICE}

In addition to publication, the present document will be posted on www.respiratoryguidelines.ca for viewing and download. A teaching and dissemination slide kit, complementing existing CTS teaching aids for the diagnosis and management of COPD, will be developed and similarly posted for viewing and download. A clinical pocket

\section{REFERENCES}

1. Ford GT, Chapman KR, Standards Committee of the Canadian Thoracic Society. Alpha1-antitrypsin deficiency: A position statement of the Canadian Thoracic Society. Can Respir J 2001;8:81-8.

2. American Thoracic Society, European Respiratory Society. American Thoracic Society/European Respiratory Society statement: Standards for the diagnosis and management of individuals with alpha-1 antitrypsin deficiency. Am J Respir Crit Care Med 2003;168:818-900.

3. Hersh CP, Dahl M, Ly NP, Berkey CS, Nordestgaard BG, Silverman EK. Chronic obstructive pulmonary disease in $\alpha 1$-antitrypsin PI MZ heterozygotes: A meta-analysis. Thorax 2004;59:843-9.

4. Sverger T. Alpha-1-antitrypsin deficiency in early childhood. Pediatrics 1978;62:22-5.

5. deSerres FJ. Worldwide racial and ethnic distribution of alpha1antitrypsin deficiency: Summary of an analysis of published genetic epidemiologic surveys. Chest 2002;122:1818-29.

6. Laurell CB, Eriksson S. The electrophoretic alpha-globulin pattern of serum in alpha-1-antitrypsin deficiency. Scand J Clin Lab Invest 1963;15:132-40.

7. Sveger T. Liver disease in alpha-1-antitrypsin deficiency detected by screening of 200,000 infants. N Engl J Med 1976;294:1316-21.

8. Eriksson S, Carison J, Velez R. Risks for cirrhosis and primary liver cancer in alpha-1-antitrypsin deficiency. N Engl J Med 1986;314:736-9.

9. Wewers MD, Casolaro MA, Sellers SE, et al. Replacement therapy for alpha 1-antitrypsin deficiency associated with emphysema. N Engl J Med 1987;316:1055-62.

10. Ad Hoc Committee on Alpha-1-Antitrypsin Replacement Therapy of the Standards Committee, Canadian Thoracic Society. Current status of alpha-1-antitrypsin replacement therapy:

Recommendations for the management of patients with severe hereditary deficiency. CMAJ 1992;146:841-4.

11. Gøtzsche PC, Johansen HK. Intravenous alpha-1 antitrypsin augmentation therapy for treating patients with alpha-1 antitrypsin deficiency and lung disease. Cochrane Database Syst Rev 2010;7:CD007851. guide summarizing key recommendations and information from the present clinical practice guideline will also be developed, and be available for viewing and download (see above).

EDITORIAL INDEPENDENCE: The Alpha-1 Antitrypsin Deficiency Expert Working Group is accountable to the CTS Respiratory Guidelines Committee and the CTS Board of Directors. The Expert Working Group is functionally and editorially independent from any funding sources of the CTS and does not receive any direct funding from external sources. The CTS receives unrestricted grants, which are combined into a central operating account to facilitate the knowledge translation activities of CTS Clinical Assemblies. Sources include the Canadian Institutes of Health Research, AstraZeneca Canada, Boehringer Ingelheim Canada, GlaxoSmithKline Inc, Pfizer and Talecris. No funders played a role in the collection, review, analysis or interpretation of the scientific literature or in any decisions regarding the recommendations or key messages presented in this document. The Expert Working Group was formed by the CTS COPD Clinical Assembly, which is accountable to the CTS Respiratory Guidelines Committee and to the CTS Board of Directors.

CONFLICTS OF INTEREST: Members of the Alpha-1 Antitrypsin Deficiency Working Group declared potential conflicts of interest at the time of appointment, and these were updated throughout the development process. Individual members' potential conflict of interest statements are posted with the online supplementary material (www.respiratoryguidelines. ca/guideline/chronic-obstructive-pulmonary-disease).

ACKNOWLEDGEMENTS: Members of the Alpha-1 Antitrypsin Deficiency Working Group thank the CTS Respiratory Guidelines Committee, T Oliver, C Lacchetti and Dr S Aaron for their expert guidance and assistance.
12. Chen S, Farahati F, Marciniuk D, Mayers I, Boudreau R, Keating T. Human Alpha 1-Proteinase Inhibitor for Patients with Alpha 1-Antitrypsin Deficiency (Technology Report No. 74). Ottawa: Canadian Agency for Drugs and Technologies in Health; 2007.

13. O'Donnell DE, Aaron S, Bourbeau J, et al. Canadian Thoracic Society recommendations for management of chronic obstructive pulmonary disease - 2007 update. Can Respir J 2007;14:5B-32B.

14. O'Donnell DE, Hernandez P, Kaplan A, et al. Canadian Thoracic Society Recommendations for Management of Chronic Obstructive Pulmonary Disease - 2008 update - highlights for primary care. Can Respir J 2008;15(Suppl A):1A-8A.

15. Rabe KF, Hurd S, Anzueto A, et al; Global Initiative for Chronic Obstructive Lung Disease. Global strategy for the diagnosis, management, and prevention of chronic obstructive pulmonary disease: GOLD executive summary. Am J Respir Crit Care Med 2007;176:532-5.

16. Brouwers M, Kho KE, Browman GP, et al; AGREE Next Step Consortium. AGREE II: Advancing guideline development, reporting, and evaluation in healthcare. CMAJ 2010;182:E839-42.

17. Guyatt G, Gutterman D, Baumann M, et al. Grading strength of recommendations and quality of evidence in clinical guidelines: Report from an American College of Chest Physicians Task Force. Chest 2006;129:178-81.

18. Harbour R, Miller J. A new system for grading recommendations in evidence based guidelines. BMJ 2001;323:334-6.

19. Ries AL, Bauldoff GS, Carlin BW, et al. Pulmonary rehabilitation. Joint ACCP/AACVPR evidence-based clinical practice guidelines. Chest 2007;131:4S-42S.

20. Sørheim IC, Bakke P, Gulsvik A, et al. $\alpha_{1}$-Antitrypsin protease inhibitor MZ heterozygosity is associated with airflow obstruction in two large cohorts. Chest 2010;138:1125-32.

21. Wencker M, Marx A, Konietzko N, Schaefer B, Campbell EJ. Screening for alpha1-Pi deficiency in patients with lung diseases. Eur Respir J 2002;20:319-24.

22. Seersholm N, Wilcke JT, Kok-Jensen A, Dirksen A. Risk of hospital admission for obstructive pulmonary disease in alpha(1)-antitrypsin heterozygotes of phenotype PiMZ. Am J Respir Crit Care Med 2000;161:81-4. 
23. Eden E, Holbrook JT, Brantly ML, Turino GM, Wise RA. Prevalence of alpha-1 antitrypsin deficiency in poorly controlled asthma - results from the ALA-ACRC low-dose theophylline trial. J Asthma 2007;44:605-8.

24. van Veen IH, ten Brinke A, van der Linden AC, Rabe KF, Bel EH. Deficient alpha-1-antitrypsin phenotypes and persistent airflow limitation in severe asthma. Respir Med 2006;100:1534-9.

25. Sansom ME, Ferry BL, Sherrell ZP, Chapel HM. A preliminary assessment of alpha-1 antitrypsin $\mathrm{S}$ and $\mathrm{Z}$ deficiency allele frequencies in common variable immunodeficiency patients with and without bronchiectasis. Clin Exp Immunol 2002;130:489-94.

26. Cuvelier A, Muir JF, Hellot MF, et al. Distribution of alpha(1)antitrypsin alleles in patients with bronchiectasis. Chest 2000;117:415-9.

27. Parr DG, Guest PG, Reynolds JH, Dowson LJ, Stockley RA. Prevalence and impact of bronchiectasis in alpha1-antitrypsin deficiency. Am J Respir Crit Care Med 2007;176:1215-21.

28. Yang P, Sun Z, Krowka MJ, et al. Alpha1-antitrypsin deficiency carriers, tobacco smoke, chronic obstructive pulmonary disease, and lung cancer risk. Arch Intern Med 2008;168:1097-103.

29. Yang P, Wentzlaff KA, Katzmann JA, et al. Alpha1-antitrypsin deficiency allele carriers among lung cancer patients. Cancer Epidemiol Biomarkers Prev 1999;8:461-5.

30. Banauch GI, Brantly M, Izbicki G, et al. Accelerated spirometric decline in New York City firefighters with $\alpha 1$-antitrypsin deficiency. Chest 2010; 138:1116-24.

31. Lougheed MD, Lemière C, Dell SD, et al; Canadian Thoracic Society Asthma Committee. Canadian Thoracic Society Asthma Management Continuum - 2010 Consensus Summary for children six years of age and over, and adults. Can Respir J 2010;17:15-24.

32. Gøtzsche PC, Johansen HK. Intravenous alpha-1 antitrypsin augmentation therapy: Systematic review. Dan Med Bul 2010;57:A4175.

33. Dirksen A, Dijkman JH, Madsen F, et al. A randomized clinical trial of alpha(1)-antitrypsin augmentation therapy. Am J Respir Crit Care Med 1999;160:1468-72.

34. Dirksen A, Piitulainen E, Parr DG, et al. Exploring the role of CT densitometry: A randomised study of augmentation therapy in alpha1-antitrypsin deficiency. Eur Respir J 2009;33:1345-53.

35. Stockley RA, Parr DG, Piitulainen E, Stolk J, Stoel BC, Dirksen A. Therapeutic efficacy of $\alpha-1$ antitrypsin augmentation therapy on the loss of lung tissue: An integrated analysis of 2 randomised clinical trials using computed tomography densitometry. Respir Res 2010;11:136-44.

36. Chapman KR, Stockley RA, Dawkins C, Wilkes MM, Navickis RJ. Augmentation therapy for alpha1 antitrypsin deficiency: A meta-analysis. COPD 2009;6:177-84.

37. Seersholm N, Wencker M, Banik N, Viskum K, Dirksen A, Kok-Jensen A, Konietzko N. Does alpha1-antitrypsin augmentation therapy slow the annual decline in $\mathrm{FEV}_{1}$ in patients with severe hereditary alpha1-antitrypsin deficiency? Wissenschaftliche
Arbeitsgemeinschaft zur Therapie von Lungenerkrankungen (WATL) alpha1-AT study group. Eur Respir J 1997;10:2260-3.

38. The Alpha-1-Antitrypsin Deficiency Registry Study Group. Survival and $\mathrm{FEV}_{1}$ decline in individuals with severe deficiency of alpha1-antitrypsin. Am J Respir Crit Care Med 1998;158:49-59.

39. Wencker M, Banik N, Buhl R, Seidel R, Konietzko N. Long-term treatment of alpha1-antitrypsin deficiency-related pulmonary emphysema with human alphal-antitrypsin. Wissenschaftliche Arbeitsgemeinschaft zur Therapie von Lungenerkrankungen (WATL)-alpha1-AT-study group. Eur Respir J 1998;11:428-33.

40. Stoller JK, Fallat R, Schluchter MD, et al. Augmentation therapy with alpha1-antitrypsin: Patterns of use and adverse events. Chest 2003;123:1425-34.

41. Gould GA, MacNee W, McLean A, et al. CT measurements of lung density in life can quantitate distal airspace enlargement - an essential defining feature of human emphysema. Am Rev Respir Dis 1988;137:380-92.

42. Tanabe N, Muro S, Hirai T, et al. Impact of exacerbations on emphysema progression in chronic obstructive pulmonary disease. Am J Respir Crit Care Med 2011;183:1653-9.

43. Dowson LJ, Guest PJ, Hill SL, Holder RL, Stockley RA. High-resolution computed tomography scanning in alpha1antitrypsin deficiency: Relationship to lung function and health status. Eur Respir J 2001;17:1097-104.

44. Dawkins PA, Dowson LJ, Guest PJ, Stockley RA. Predictors of mortality in alpha1-antitrypsin deficiency. Thorax 2003;58:1020-6.

45. Dirksen A, Piitulainen E, Parr DG, et al. Exploring the role of CT densitometry: A randomized study of augmentation therapy in alpha1-antitrypsin deficiency. Eur Respir J 2009;33:1345-53.

46. Mascalchi M, Diciotti S, Sverzellati N, et al. Low agreement of visual rating for detailed quantification of pulmonary emphysema in whole-lung CT. Acta Radiol 2012;53:53-60.

47. Marciniuk DD, Goodridge D, Hernandez P, et al. Managing dyspnea in patients with advanced chronic obstructive pulmonary disease: A Canadian Thoracic Society clinical practice guideline. Can Respir J 2011;18:69-78.

48. Zorzetto M, Russi E, Senn O, et al; SAPALDIA Team. SERPINA1 gene variants in individuals from the general population with reduced alpha1-antitrypsin concentrations. Clin Chem 2008;54:1331-8.

49. Abboud RT, Nelson TN, Jung B, Mattman A. Alpha1-antitrypsin deficiency: A clinical-genetic overview. Appl Clin Genet 2011;4:55-65.

50. Sandhaus RA. Alpha-1 antitrypsin deficiency: Whom to test, whom to treat? Semin Respir Crit Care Med 2010;31:343-7.

51. Janciauskiene S, Ferrarotti I, Laenger F, Jonigk D, Luisetti M. Clinical utility gene card for a-1-antitrypsin deficiency. Eur J Hum Genet 2011; doi:19:10.1038/ejhg.2010.246.

52. Silverman EK, Sandhaus RA. Alpha1-antitrypsin deficiency. N Engl J Med 2009;360:2749-57. 


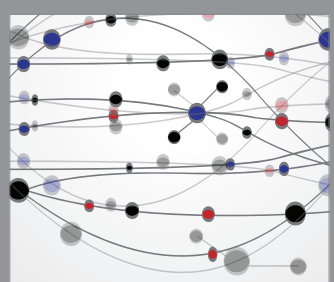

The Scientific World Journal
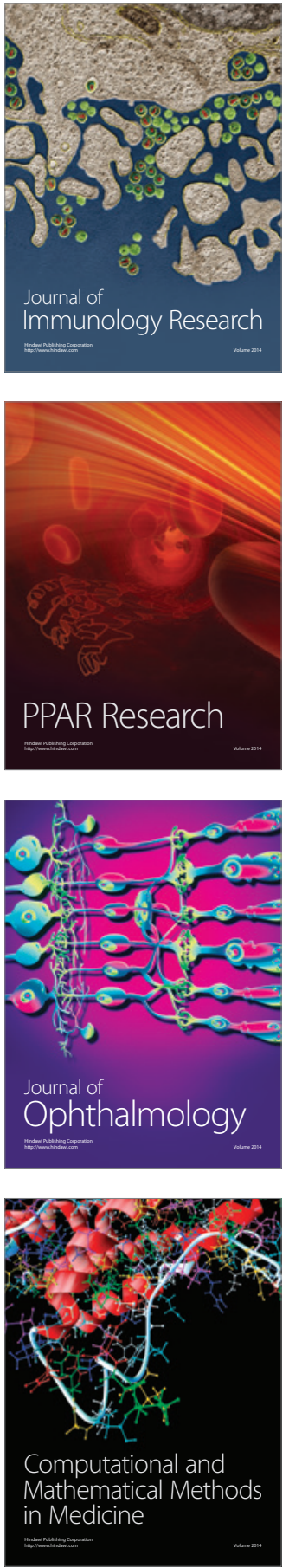

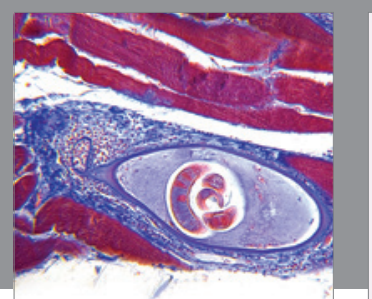

Gastroenterology Research and Practice

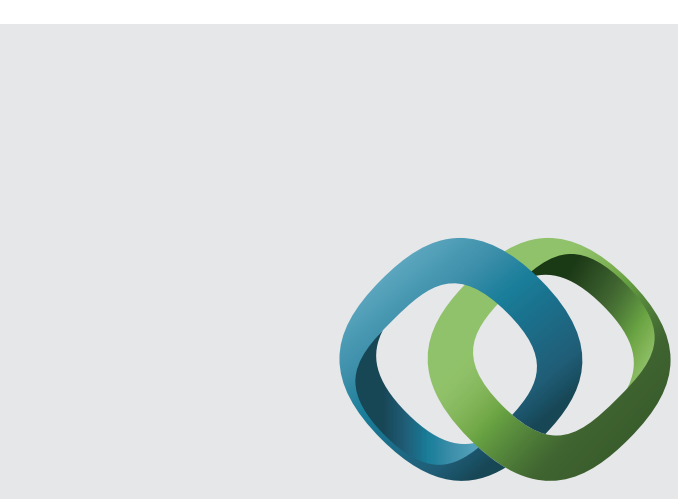

\section{Hindawi}

Submit your manuscripts at

http://www.hindawi.com
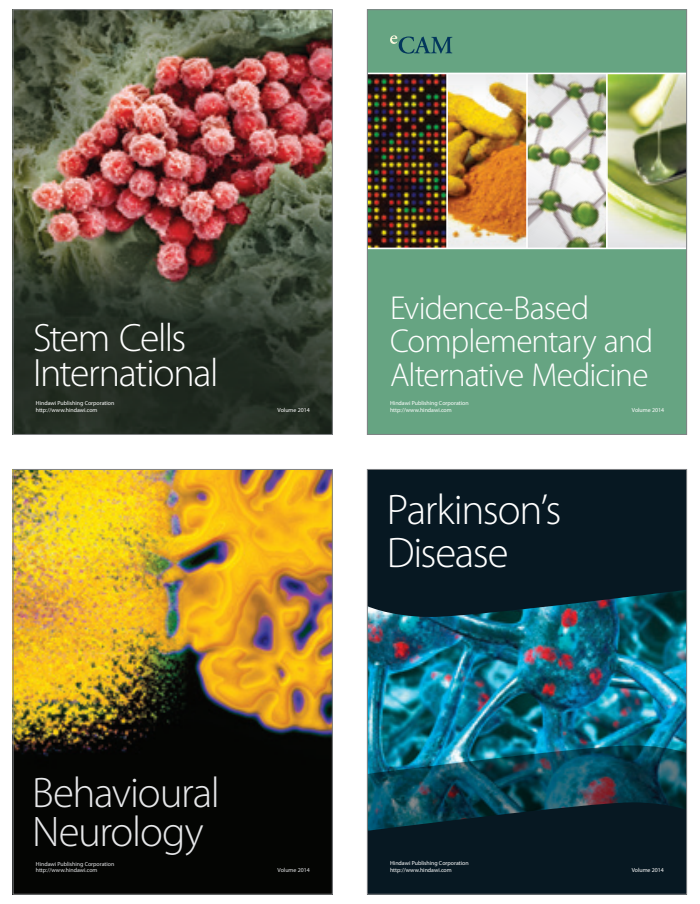
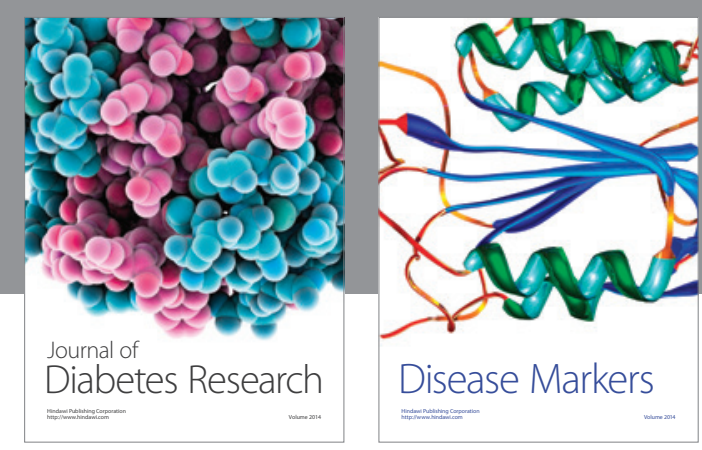

Disease Markers
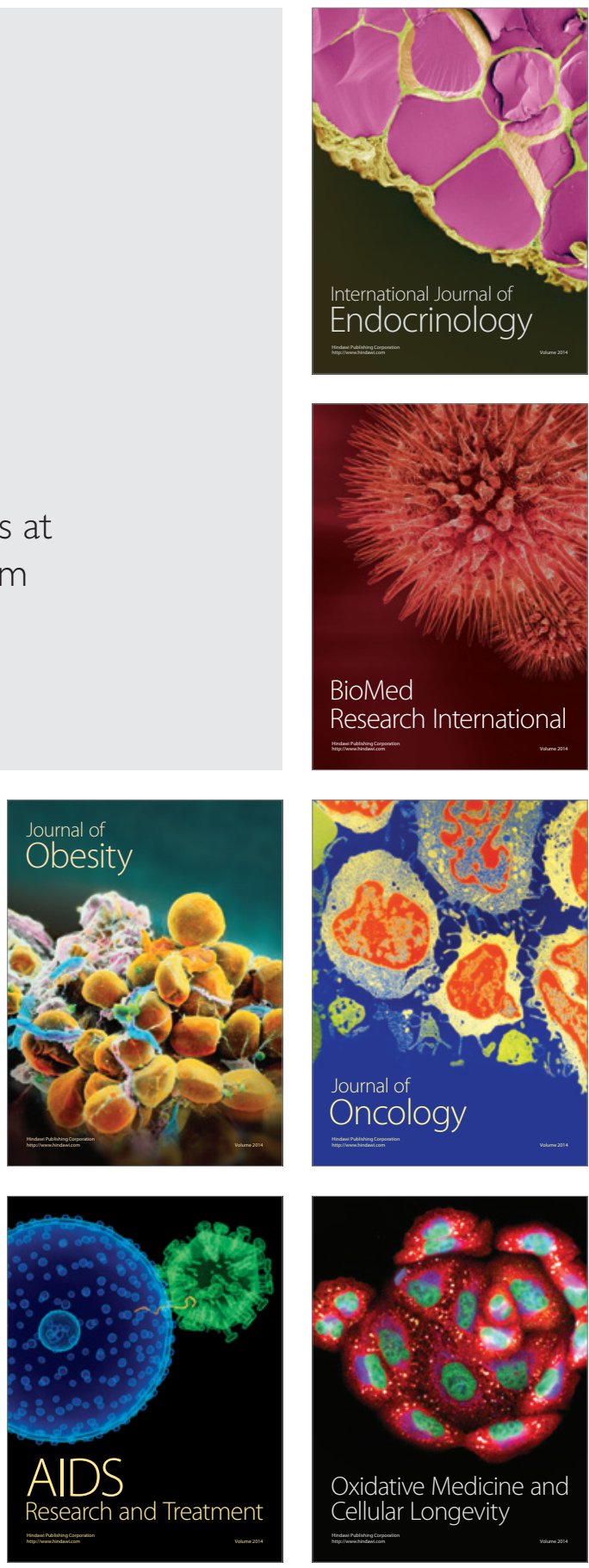